Jurnal Pemikiran \& Penelitian Psikologi

\title{
PSIKOLOGIA
}

p-ISSN: $185-0327$

e-ISSN: $2549-2136$

www.jurnal.usu.ac.id/psikologia

\section{HUBUNGAN PERSEPSI DUKUNGAN SOSIAL KELUARGA DENGAN SELF REGULATED LEARNING MAHASISWI PROGRAM MAGISTER USU YANG TELAH MENIKAH}

THE RELATIONSHIP OF FAMILY SOCIAL SUPPORT PERCEPTION WITH SELF REGULATED LEARNING UNIVERSITAS SUMATERA UTARA MASTER DEGREE STUDENTS WHO HAS BEEN MARRIED

Filisia Ayunani dan Filia Dina Anggaraeni Psikologia: Jurnal Pemikiran \& Penelitian Psikologi Tahun 2018, Vol. 13, No. 3, hal.162-171 Artikel ini dapat diakses dan diunduh pada: www.jurnal.usu.ac.id/psikologia

Dipublikasikan oleh:

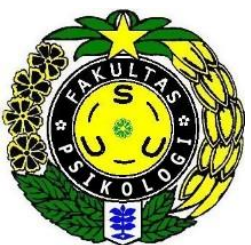

Fakultas Psikologi

Universitas Sumatera Utara

Jl. Dr. Mansyur No. 7 Medan. Telp/fax: 061-8220122

Email: psikologia@usu.ac.id 


\title{
HUBUNGAN PERSEPSI DUKUNGAN SOSIAL KELUARGA DENGAN SELF REGULATED LEARNING MAHASISWI PROGRAM MAGISTER USU YANG TELAH MENIKAH
}

\author{
Filisia Ayunani dan Filia Dina Anggaraeni \\ Universitas Sumatera Utara
}

\begin{abstract}
ABSTRAK
Penelitian ini bersifat korelasional yang bertujuan untuk mengetahui hubungan persepsi dukungan sosial keluarga dengan self regulated learning mahasiswi program magister (S2) yang telah menikah dengan menggunakan pendekatan kuantitatif melalui skala sebagai alat pengumpulan data. Data didapat dari 70 orang mahasiswi S2 Universitas Sumatera Utara (USU) yang telah menikah, yang diambil dengan teknik proposional sampling. Data bersifat normal dan linear sehingga analisa data menggunakan korelasi Product Moment dari Person.
\end{abstract}

Hasil analisa data menunjukkan koefisien korelasi sebesar 0, 46, sehingga dapat diambil kesimpulan bahwa ada hubungan positif antara persepsi dukungan sosial keluarga dengan self regulated learning mahasiswi S2 USU yang telah menikah. Semakin tinggi persepsi dukungan sosial keluarga maka semakin tinggi self regulated learning. Sebaliknya, semakin rendah persepsi dukungan sosial keluarga maka semakin rendah self regulated learning pada mahasiswi S2 USU yang telah menikah.

Kata kunci : persepsi dukungan sosial keluarga, self regulated learning

\section{THE RELATIONSHIP OF FAMILY SOCIAL SUPPORT PERCEPTION WITH SELF REGULATED LEARNING UNIVERSITAS SUMATERA UTARA MASTER DEGREE STUDENTS WHO HAS BEEN MARRIED}

\section{ABSTRACTS}

This study is to measure correlation between family social support perception and self regulated learning in University North of Sumatra master degree students who has been married through quantitative approach. The scale has been used to collect data by using propotional sampling technique from 70 university North of Sumatra magister program students. Data is normal and linear, therefore the analysis is done by using Product Moment correlation from Person.

The result of the data shows the correlation coefficient as much as 0,46 , so it can be concluded that there is relationship between family social support perception and self regulated learning in University North Sumatra master degree students who has been married. The higher of family social support perception, the higher self regulated learning on University North Sumatra magister program students. In the contrary, the lower family social support perception, the lower self regulated learning on University North Sumatra magister program students.

Keywords : family social support perception, self regulated learning

Rekomendasi mensitasi:

Ayunani, F., Anggaraeni, F.D. (2018). Hubungan

*Korespondensi mengenai penelitian ini dapat dilayangkan kepada: psikologia@usu..ac.id
Persepsi Dukungan Sosial Keluarga dengan SelfRegulated Learning Mahasiswi Program Magister USU yang Telah Menikah.. Psikologia :Jurnal Pemikiran dan Penelitian Psikologi, 13(3), 162-171 
Program Magister adalah program pendidikan jenjang/ strata dua (S2) yang ditujukan untuk memperoleh gelar magister. Mahasiswa S2 harus menyelesaikan 39 sampai 50 sks selama kurun waktu empat sampai sepuluh semester (Webmaster Dikti, 2012). Program S2 adalah kelanjutan program S1, oleh karena itu mata kuliah di S2 lebih advance dan yang dipelajari adalah sub-bidang yang lebih spesifik. Mahasiswa S1 mempelajari (satu atau lebih) metode, sedangkan mahasiswa S2 mengembangkan metode. Oleh karena itu, tugas akhir mahasiswa $\mathrm{S} 1$ adalah mengaplikasikan suatu metode untuk menyelesaikan sebuah persoalan, sedangkan tesis $\mathrm{S} 2$ mengembangkan metode yang spesifik agar dapat diaplikasikan untuk persoalan yang lebih luas (Munir, 2013). Program magister biasanya dipenuhi oleh mahasiswa yang rata-rata usianya di atas 20 tahun.

Menurut Papalia, Old, dan Feldman (2008) usia antara 20 hingga 40 tahun merupakan usia dewasa awal. Havighurst (dalam Hurlock, 1999) mengatakan bahwa masa ini merupakan masa memilih pasangan, mulai membina keluarga, mengelola rumah tangga, mengasuh anak, serta mencari kelompok sosial yang menyenangkan. Dalam hal ini berarti tidak menutup kemungkinannya bahwa mahasiswa yang mengikuti program studi magister telah menikah atau menikah pada masa studi S2 nya. Mahasiswi S2 yang telah menikah, harus menjalani dua peran sekaligus yaitu sebagai mahasiwa dan sebagai istri. Kedua peran ini mempunyai tugas dan tanggung jawab masing-masing. Sebagai mahasiswa dituntut untuk mencapai hasil belajar yang optimal ditambah menjadi seorang istri dituntut mampu mengerjakan pekerjaan rumah tangga, mengurus suami, menyesuaikan diri satu sama lain, memahami pasangan hidup baru, serta bagaimana mendidik anak (Hurlock, 1999). Selain itu juga sebagai ibu memiliki peran pengasuhan dan pendidikan anak, pelindung dan sebagai salah satu kelompok dari peranan sosialnya serta sebagai anggota masyarakat dari lingkungannya, disamping itu juga ibu dapat berperan sebagai pencari nafkah tambahan dalam keluarganya (Effendi, 1998). Hal ini tentu berbeda dengan mahasiswi yang belum menikah.

Berdasarkan survey yang dilakukan peneliti pada sampel 22 subjek mahasiswi program magister pada beberapa fakultas di Universitas Sumatera Utara diperoleh bahwa penyelesaian yang mereka lakukan atas kendala yang dihadapi ketika kuliah dengan status telah menikah adalah dengan mengatur waktu dengan baik, menentukan prioritas mana yang lebih penting, melakukan diskusi dengan suami, mengulang pelajaran di rumah, membuat schedule belajar. Dalam hal ini berarti ada mahasiswi yang melakukan pengaturan diri dalam belajar dengan baik. Pengaturan diri dalam belajar untuk mencapai hasil belajar yang optimal disebut dengan self regulated learning. Penelitian yang dilakukan Azlina (2007) mengenai self regulated learning dan pencapaian akademik pada mahasiswa Malaysia mengatakan bahwa self regulated learning adalah prediktor signifikan pada pencapaian akademik. Hal ini sejalan dengan pendapat Cobb (2003) yang menemukan hubungan signifikan antara perilaku self regulated learning dengan prestasi akademik.

Menurut Zimmerman (1990), dalam teori sosial kognitif terdapat tiga hal yang mempengaruhi seseorang melakukan 
self regulated learning yaitu individu, perilaku, dan lingkungan. Keluarga yang termasuk dalam factor lingkungan sangat berpengaruh terhadap keberhasilan individu dalam hal belajar (Dalyono, 2007). Keluarga adalah pasangan perkawinan dengan atau tanpa anak (Houton, \& Hunt, 1987). Dengan kata lain hubungan perkawinan yang terdiri dari suami dan istri dapat dikatakan sebuah keluarga. Salah satu bentuk penguatan tersebut berupa dukungan penghargaan. Dukungan penghargaan merupakan dukungan sosial yang terjadi apabila terdapat ekspresi penilaian positif terhadap individu, pemberian semangat, persetujuan pada pendapat, perbandingan yang positif dengan individu lain. Dalam penelitian ini dukungan sosial keluarga yang dimiliki mahasiswi magister yang telah menikah adalah suami.

\section{Self Regulated Learning}

Zimmerman

mendefenisikan self regulated learning sebagai proses belajar dimana peserta didik menggunakan strategi personal untuk mengatur perilaku dan lingkungan belajar secara langsung. Strategi dalam pendekatan belajar dapat membantu peserta didik membentuk kebiasaan belajar yang lebih baik dan memperkuat kemampuan mereka dalam belajar, menerapkan strategi belajar untuk meningkatkan hasil akademik, memilih atau mengatur lingkungan fisik untuk mendukung belajar dan mengatur waktu mereka secara efektif (Zimmerman, dalam Maharani, 2009). Kategori strategi self regulated learning yaitu evaluasi terhadap kemajuan tugas (self evaluating), mengatur materi pelajaran (organizing dan transforming), membuat rencana dan tujuan belajar (goal setting and planning), mencari informasi (seeking information), mencatat hal penting (keeping record and monitoring), mengatur lingkungan belajar (environmental structuring), konsekuensi setelah mengerjakan tugas (self consequences), mengulang dan mengingat (rehearsing and memorizing), meminta bantuan teman sebaya (seeking assistancefrom peers), meminta bantuan guru (seeking assistance from teacher), meninjau kembali buku teks (reviewing the textbook), meninjau kembali catatan (reviewing the notes), meninjau kembali tes sebelumnya dan menyiapkan tes (reviewing the previous tests and assignment in preparation for a test) (Zimmerman \& Martinez-Pons, 1986).

\section{Persepsi Dukungan Sosial Keluarga}

Menurut KBBI, persepsi adalah tanggapan (penerimaan) langsung dari sesuatu atau proses seseorang mengetahui beberapa hal melalui panca indranya. Menurut Sarafino (2006) dukungan sosial adalah berbagai dukungan yang diterima seseorang dari orang lain, dapat berupa dukungan emosional, dukungan penghargaan, dukungan instrumental, serta dukungan informasi. Keluarga adalah dua atau individu yang tergabung karena hubungan perkawinan dan mereka hidup dalam satu rumah tangga, berinteraksi satu sama lain, dan di dalam perannya masingmasing menciptakan serta mempertahankan kebudayaan (Bailon \& Maglaya, dalam Effendy 1998). Hubungan perkawinan yang terdiri dari suami dan istri saja dapat dikatakan sebuah keluarga (Houton \& Hunt, 1987).

Dengan kata lain persepsi dukungan sosial keluarga adalah tanggapan individu terhadap kenyamanan fisik dan psikologis yang dapat berupa 
dukungan dukungan emosional, dukungan penghargaan, dukungan instrumental, dukungan informasi, yang diberikan oleh anggota keluarga yaitu suami untuk menghadapi setiap permasalahan yang terjadi dalam kehidupan.Dimensi pada dukungan social meliputi (Sarafino, 2006):

1. Dukungan instrumental. Bentuk dukungan ini dapat mengurangi stres karena ini dapat langsung memecahkan masalahnya yang berhubungan dengan materi.

2. Dukungan informasional. Jenis informasi seperti ini dapat menolong individu untuk mengenali dan mengatasi masalah dengan lebih mudah.

3. Dukungan emosional. Bentuk dukungan ini membuat individu memiliki perasaan nyaman, yakin, diperdulikan dan dicintai oleh sumber dukungan sosial sehingga individu dapat menghadapi masalah dengan lebih baik.

\section{HIPOTESIS PENELITIAN}

Hipotesa dalam penelitian ini adalah: ada hubungan positif antara persepsi dukungan sosial keluarga dengan self regulated learning mahasiswi S2 USU yang telah menikah.

\section{METODE Variabel Penelitian}

Variabel-variabel yang digunakan dalam penelitian ini adalah:

$\mathrm{X}_{1} \quad$ : Dukungan Sosial

Keluarga

$$
\mathrm{X}_{2} \quad \text { : Self Regulated Learning }
$$

\section{Partisipan}

Jumlah partisipan dalam penelitian ini adalah 70 orang mahasiswi aktif program magister (S2) USU yang telah menikah dengan menggunakan teknik proporsional sampling.

\section{Gambaran Umum Partisipan}

Total partisipan adalah 70 orang dengan rincian berasal dari 39 program studi yang ada di USU. Partisipan penelitian dijabarkan berdasarkan usia, pekerjaan, serta masa studi mahasiswi.

Tabel 1. Gambaran Subjek Penelitian

Berdasarkan Usia

\begin{tabular}{clcc}
\hline No. & Rentang Usia & Jumlah & Persentase \\
\hline 1. & $\begin{array}{l}20-40 \text { (dewasa } \\
\text { muda) }\end{array}$ & 53 & $75,71 \%$ \\
2. & $\begin{array}{l}40-60 \text { (dewasa } \\
\text { madya) }\end{array}$ & 17 & $24,29 \%$ \\
\hline & Total & 70 & $100 \%$ \\
\hline
\end{tabular}

Tabel 2. Gambaran Subjek Penelitian

Berdasarkan Pekerjaan

\begin{tabular}{cccc}
\hline No. & Status Pekerjaan & Jumlah & Persentase \\
\hline 1. & Bekerja & 56 & $75 \%$ \\
2. & Tidak Bekerja & 14 & $25 \%$ \\
\hline & Total & 70 & $100 \%$
\end{tabular}

Tabel 3. Gambaran Subjek Penelitian Berdasarkan Masa Kuliah

\begin{tabular}{cccc}
\hline No. & Masa Kuliah & Jumalah & Persentase \\
\hline 1. & 2 semester & 26 & $37 \%$ \\
2. & 4 semester & 35 & $50 \%$ \\
3. & > 4 semester & 9 & $13 \%$ \\
\hline & Total & 70 & $100 \%$ \\
\hline
\end{tabular}

\section{Alat Ukur}

Pada penelitian ini, pengumpulan data dilakukan dengan menggunakan skala. Terdapat 2 (dua) skala yang digunakan yaitu skala persepsi dukungan social dan skala self regulated learning. Skala disajikan dalam bentuk pernyataan favorable (pernyataan mendukung) dan unfavorable (pernyataan tidak mendukung). Nilai setiap pilihan bergerak dari $1-4$. Bobot penilaian untuk pernyataan favorable yaitu: $\mathrm{TP}=1, \mathrm{JR}=2, \mathrm{SR}=3, \mathrm{SL}=4$. 
Sedangkan bobot penilaian untuk pernyataan unfavorable yaitu: $\mathrm{TP}=4, \mathrm{JR}=3$, $\mathrm{SR}=2, \mathrm{SL}=1$.

\section{Uji Realibilitas dan Uji Daya} Diskriminasi Aitem

1. Skala 1 - Persepsi Dukungan Sosial

Hasil uji coba alat ukur dilakukan melalui dua kali putaran agar memperoleh reliabilitas yang memenuhi standar ukur dan daya diskriminasi aitem ( $r i x)$ lebih besar sama dengan 0.30. Pada putaran pertama, reliabilitas alat ukur yang diujicobakan adalah 0.857 dan terdapat 5 aitem yang memiliki indeks daya diskriminasi aitem dibawah 0.30. Pada putaran kedua, reliabilitas alat ukur yang diujicobakan adalah sebesar 0.881 dan semua aitem memiliki indeks daya diskriminasi aitem di atas 0.30 .

2. Skala 2 - Self Regulated Learning

Hasil uji coba alat ukur dilakukan melalui tiga kali putaran agar memperoleh reliabilitas yang memenuhi standar ukur dan daya diskriminasi aitem ( $r$ ix) lebih besar sama dengan 0.30. Pada putaran pertama, reliabilitas alat ukur yang diujicobakan adalah 0.921 dan terdapat 24 aitem yang memiliki indeks daya diskriminasi aitem dibawah 0.30. Pada putaran kedua, reliabilitas alat ukur yang diujicobakan adalah sebesar 0.925 dan terdapat 2 aitem yang memiliki indeks daya diskriminasi aitem dibawah 0.30. Pada putaran ketiga, reliabilitas alat ukur yang diujicobakan adalah sebesar 0.924 dan semua aitem memiliki indeks daya diskriminasi aitem di atas 0.30 .

\section{Teknik Analisa Data}

Analisis data yang digunakan dalam penelitian ini adalah statistik. ). Statistik yang digunakan untuk menguji hipotesis ini adalah teknik analisis korelasi Product Moment dari Pearson dengan menggunakan program SPSS (Statistic Package for Social Science) release 16.0 for window.

\section{Uji Normalitas}

$\begin{array}{crr}\text { Uji } & \text { normalitas } & \text { sebaran } \\ \text { menggunakan } & \text { analisis } & \text { statistik }\end{array}$

Kolmogorov-Smirnov. Data dikatakan terdistribusi normal jika harga $\mathrm{p}>0.05$. Hasil uji normalitas dengan menggunakan Kolmogorov-Smirnov adalah sebagai berikut :

Tabel 4. Uji Normalitas

\begin{tabular}{lccc}
\hline \multicolumn{1}{c}{ Variabel } & $\begin{array}{c}\text { Signifikansi } \\
(2 \text { tailed })\end{array}$ & $\begin{array}{c}\text { Z } \\
\text { score }\end{array}$ & Distribusi \\
\hline $\begin{array}{l}\text { Self Regulated } \\
\text { Learning }\end{array}$ & 0.97 & 0.488 & Normal \\
$\begin{array}{l}\text { Persepsi } \\
\text { Dukungan }\end{array}$ & 0.681 & 0.719 & Normal \\
Sosial Keluarga & & & \\
\hline
\end{tabular}

\section{Uji Linearitas}

Uji linearitas dilakukan dengan menggunakan test for linearity, yang menunjukkan bahwa data variabel dukungan sosial keluarga berkorelasi secara linear terhadap self regulated learning. Data penelitian dikatakan berkorelasi secara linear apabila $\mathrm{p}<0.05$ untuk linearity dan nilai Sig pada Deviation From Linearity nilainya $>0,05$. Hasil uji linearitas dapat dilihat pada tabel berikut :

Tabel 5. Uji Linearitas

\begin{tabular}{cccc}
\hline Variabel & $\begin{array}{c}\text { Sig. } \\
\text { Linearity }\end{array}$ & $\begin{array}{c}\text { Sig. } \\
\text { Deviation } \\
\text { From } \\
\text { Linearity }\end{array}$ & $\begin{array}{c}\text { Keteran } \\
\text { gan }\end{array}$ \\
\hline $\begin{array}{c}\text { Dukungan } \\
\text { Sosial }\end{array}$ & & & \\
$\begin{array}{c}\text { Keluarga* Sel } \\
f \text { Regualated } \\
\text { Learning }\end{array}$ & 0.000 & 0.053 & Linear \\
\hline
\end{tabular}

\section{HASIL}

Korelasi Antar Variabel 
Setelah dilakukan analisis korelasi pada data penelitian dukungan sosial keluarga dengan self regulated learning maka didapat koefisien korelasi (r) sebesar 0.460 dan $p=0.000$. Dengan nilai $p<0.05$ ini berarti $\mathrm{H}_{0}$ ditolak. Artinya, pada tingkat kepercayaan $95 \%$, ada hubungan positif antara perspsi dukungan sosial keluarga dengan self regulated learning pada mahasiswi S2 USU yang telah menikah. Semakin tinggi persepsi dukungan sosial keluarga maka semakin tinggi self regulated learning pada mahasiswi S2 USU yang telah menikah. Sebaliknya, semakin rendah persepsi dukungan sosial keluarga maka semakin rendah self regulated learning pada mahasiswi S2 USU yang telah menikah. Dengan nilai $r=$ 0.460 dapat dikatakan bahwa kekuatan korelasi antara persepsi dukungan sosial keluarga memiliki hubungan yang sedang dengan self regulated learning. Kesimpulan tersebut dilihat dari tabel berikut.

Tabel 6. Korelasi antara Dukungan Sosial Keluarga dengan Self Regulated Learning

\begin{tabular}{llrr}
\hline \multicolumn{3}{c}{ Correlations } & \\
\hline & & SRL & PDKS \\
\cline { 3 - 4 } Persepsi & Pearson Correlation & 1 & $.460^{* *}$ \\
Dukungan Sosial & Sig. (1-tailed) & & .000 \\
Keluarga & $\mathrm{N}$ & 70 & 70 \\
Self Regulated & Pearson Correlation & $.460^{* *}$ & 1 \\
Learning & Sig. (1-tailed) & .000 & \\
& $\mathrm{~N}$ & 70 & 70 \\
\hline
\end{tabular}

\section{Kategorisasi Data}
Berdasarkan kategorisasi subjek penelitian secara empirik, data dikelompokkan dalam tingkatan-tingkatan utnuk kemudian disusun menurut norma tertentu. Untuk kriteria variabel persepsi dukungan sosial keluarga mahasiswi program magister USU yang telah

menikah dengan frekuensi dan presentase dapat dilihat pada table berikut :

Tabel 7. Kategorisasi Subjek pada Variabel Persepsi Dukungan Sosial Keluarga

\begin{tabular}{ccccc}
\hline Variabel & Rentang nilai & Kategori & Jumlah & Persentase \\
\hline Persepsi & $X \geq 65.322$ & Tinggi & 11 Orang & $15.71 \%$ \\
Dukungan & $50.618 \leq X<$ & Sedang & 49 Orang & $70 \%$ \\
Sosial & 65.332 & Rendah & 10 Orang & $14.29 \%$ \\
Keluarga & $X<50.618$ & Renda & 70 orang & $100 \%$ \\
\hline Total & & &
\end{tabular}

Tabel 8. Kategorisasi Subjek pada Variabel Self Regulated Learning

\begin{tabular}{ccccc}
\hline Variabel & Rentang nilai & Kategori & Jumlah & Persentase \\
\hline Self & $X \geq 174,278$ & Tinggi & 13 Orang & $18,57 \%$ \\
Regulated & $137,002 \leq X<$ & Sedang & 48 Orang & $68,57 \%$ \\
Learning & 174,278 & & & \\
& $X<137,002$ & Rendah & 9 Orang & $12,86 \%$ \\
\hline Total & & & 70 orang & $100 \%$ \\
\hline
\end{tabular}

\section{DISKUSI}

Berdasarkan hasil utama yang diperoleh dari hasil penelitian ini yang terdiri dari 70 subjek penelitian maka diperoleh korelasi antara persepsi dukungan sosial keluarga dengan self regulated learning pada mahasiswi S2 USU yang telah menikah. Berdasarkan hasil penelitian diperoleh adanya korelasi positif antara persepsi dukungan sosial keluarga dengan self regulated learning pada mahasiswi S2 USU yang telah menikah $(r=0.460$ dengan $\mathrm{p}=0,000$ dan $\mathrm{p}$ $<0,05)$. Ini berarti bahwa Ho ditolak dan Ha diterima yang artinya bahwa ada hubungan positif antara persepsi dukungan sosial keluarga dengan self regulated learning mahasiswi S2 USU yang telah menikah. Artinya semakin tinggi persepsi dukungan sosial keluarga maka semakin tinggi self regulated learning pada mahasiswi S2 USU yang telah menikah. Sebaliknya, semakin rendah persepsi 
dukungan sosial keluarga maka semakin rendah juga self regulated learning pada mahasiswi S2 USU yang telah menikah. Dengan demikian dapat dikatakan bahwa persepsi dukungan sosial keluarga dapat dipandang sebagai salah satu pendorong mahasiswi S2 dalam belajar untuk menggunakan berbagai strategi belajar dalam meregulasi dirinya mencapai tujuan yang ditetapkan.

Hubungan antara persepsi dukungan sosial keluarga dengan self regulated learning menunjukkan bahwa indvidu dengan persepsi dukungan sosial rendah tidak menggunakan strategi self regulated learning sebanyak individu dengan perspsi dukungan sosial keluarga tinggi. Berdasarkan hasil perbandingan antar skor empirik dan skor mean hipotetik untuk skala perspsi dukungan sosial keluarga menunjukkan bahwa mean empirik lebih besar dari mean hipotetik $(57,97>47,5)$. Hal ini berarti bahwa secara umum persepsi dukungan sosial keluarga yang diteliti lebih tinggi dibandingkan dengan populasi yang diasumsikan. Begitu juga dengan hasil perbandingan antara skor mean empirik dengan skor mean hipotetik untuk skala self regulated learning menunjukkan bahwa mean empirik lebih besar dari mean hipotetik $(155,64>130)$. Hal ini berarti bahwa secara umum self regulated learning mahasiswi S2 USU yang diteliti lebih tinggi dibandingkan dengan populasi yang diasumsikan.

Berdasarkan kategorisasi, subjek yang berada dalam kategori persepsi dukungan sosial keluarga yang tinggi berjumlah 11 orang (15. 75\%) dari 70 orang mahasiswi S2 USU yang telah menikah, subjek yang berada dalam kategori persepsi dukungan sosial keluarga rendah berjumlah 10 orang (14.29\%).
Sedangkan subjek yang berada dalam kategori sedang berjumlah 49 orang $(70 \%)$ dari 70 orang mahasiswi S2 yang telah menikah. Hal ini dapat diartikan bahwa sebagian besar mahasiswi memiliki persepsi dukungan sosial keluarga yang sedang.

Berdasarkan kategorisasi, subjek yang berada dalam kategori self regulated learning yang tinggi berjumlah 13 orang (18.57\%) dari 70 mahasiswi S2 yang telah menikah. Subjek yang berada dalam kategori self regulated learning yang rendah 9 orang $(12.86 \%)$ dari 70 orang mahasiswi S2 yang telah menikah. Sedangkan subjek yang berada dalam kategori sedang berjumlah 48 orang (68.57\%) dari 70 mahasiswi S2 USU yang telah menikah. Hal ini dapat diartikan bahwa sebagian besar mahasiswi memiliki self regulated learning sedang.

\section{KESIMPULAN}

1. Dari hasil penelitian, ada hasil hubungan positif antara persepsi dukungan sosial keluarga dengan self regulated learning pada mahasiswi S2 USU yang telah menikah.

2. Secara umum, persepsi dukungan sosial keluarga lebih tinggi dibandingkan dengan populasi yang diasumsikan.

3. Secara umum, self regulated learning mahasiswi lebih tinggi dibandingkan dengan populasi yang diasumsikan.

\section{SARAN}

\section{Saran Metodologis}

Berikut ini adalah beberapa saran metodologis yang penting untuk dipertimbangkan, yaitu: 
1. Bagi peneliti selanjutnya yang ingin meneliti topik yang sama diharapkan dapat mengontrol faktor-faktor lain yang diperkirakan dapat mempengaruhi self regulated learning selain persepsi dukungan sosial, seperti motivasi dan self efficacy.

2. Bagi peneliti selanjutnya yang akan melakukan kajian sejenis, hendaknya data persepsi dukungan sosial dengan self regulated learning diperoleh tidak hanya menggunakan skala sebagai alat ukur penelitian, tetapi dapat menambahkan dengan metode wawancara. Dengan digunakannya metode ini diharapkan dapat memperkaya informasi dalam memperoleh data yang lebih rinci.

3. Bagi peneliti selanjutnya yang ingin meneliti variabel perspsi dukungan sosial keluarga dan self regulated learning sebaiknya penelitian dilakukan dengan subjek lebih banyak, agar generalisasi dari hasil penelitian lebih luas.

4. Bagi peneliti selanjutnya diharapkan dapat lebih banyak lagi mengumpulkan informasi dan literatur tentang persepsi dukungan sosial dengan self regulated learning.

\section{Saran Praktis}

1. Hasil penelitian ini menunjukkan bahwa adanya hubungan antara persepsi dukungan sosial keluarga denga self regulated learning mahasiswi S2 USU yang telah menikah. Sehingga diharapkan persepsi dukungan sosial dengan self regulated learning mahasiwi semakin meningkat.

2. Persepsi dukungan sosial dapat dijadikan salah satu sumber untuk meningkatkan self regulated learning pada mahasiswi USU yang telah menikah untuk proses pembelajarnnya.

\section{REFERENSI}

Azlina, Mohd Kasim. (2007). Self Regulated Learning \& Academic Achievement in Malaysian undergraduates. International Education Journal, 2007, 8(1), 221228 ISSN 1443-1475 Shannon research press

Cobb, R.J., (2003). The Relationship Between Self-Regulated Learning Behaviors and Academic Performance in Web-Based Course. Disertation, Virginia: Blacksburg.

Dalyono, M. (2007). Psikologi Pendidikan. Jakarta: Rineka Cipta

Effendi, Nasrul. (1998). Dasar-dasar Keperawatan Kesehatan Masyarakat, edisi 2. Jakarta: EGC

Horton, B. Paul \& Hunt, L. Chester. (1987). Sosiologi Jilid I. Jakarta: Erlangga

Hurlock, E. B. (1999). Psikologi Perkembangan: Suatu Pendekatan Sepanjang Rentang Kehidupan. Edisi Kelima. Jakarta: Penerbit Erlangga.

Munir, Rinaldi. (2013). Perbedaan S1, S2, S3.

http://rinaldimunir.wordpress.com/ 2013/04/24/perbedaan-s1-s2-dans3/. Tanggal akses 4 Januari 2013

Papalia, Diane E., Old, Sally Wendoks., \& Fledment, Ruth Duskin. (2008). Human Developmet. Jakarta: Kencana

Sarafino, Edward P. (2006). Health Psychology: Biopsychosocial Interactions.. United States of America : Wiley \& Sons Inc. 
Webmaster Dikti. (2012). Sistem

Pendidikan Tinggi 2011. [online] http://www.dikti.go.id/?page_id=6

8\&lang=id. Tanggal akses 15

Desember 2012

Zimmerman, B. J \& Martinez-Pons, M.

(1986). Developmen of a Structured Interview for Assessing

Student Use of Self-Regulated

Learning Strategies. Journal

Educational American, Vol 23, No

4, Pp. 614-628 